\title{
Statyba
}

\section{THE EQUILIBRIUM MOISTURE OF BUILDING ENCLOSURES AS FUNCTION OF CALCULATED CLIMATIC PARAMETERS}

\section{Gnip , V. Keršulis \& S. Vejjelis}

To cite this article: I. Gnip , V. Keršulis \& S. Vejelis (2001) THE EQUILIBRIUM MOISTURE OF BUILDING ENCLOSURES AS FUNCTION OF CALCULATED CLIMATIC PARAMETERS, Statyba, 7:1, 60-67, DOI: $10.1080 / 13921525.2001 .10531700$

To link to this article: https://doi.org/10.1080/13921525.2001.10531700

Published online: 30 Jul 2012.

Submit your article to this journal $\llbracket$

LII Article views: 57 


\title{
РАВНОВЕСНАЯ ВЛАЖНОСТЬ ОГРАЖДАЮЩИХ КОНСТРУКЦИЙ ЗДАНИЙ КАК ФУНКЦИЯ РАСЧЕТНЫХ КЛИМАТИЧЕСКИХ ПАРАМЕТРОВ
}

\author{
И. Гнип, В. Кершулис, С. Веялис
}

Институт "Термоизоляция"

\section{1. Введение}

В ограждающих конструкциях при продолжительной и регулярной эксплуатации после определенного периода времени влагосодержание материалов приближается к стабильному (равновесному) состоянию. Равновесная влажность одних и тех же материалов в различных ограждениях не одинакова и зависит от свойств материалов, конструкции ограждения и условий эксплуатации. Микроклимат помещений обусловлен нормативными требованиями [1]. Определяющее влияние на влажностный режим ограждений оказывают климатические параметры, которые переменны и при определенных усреднениях изменяются по известным законам [2, 3].

\section{2. Равновесная влажность ограждений как} функция расчетных климатических параметров

Равновесная влажность материала в ограждении является следствием двух основных физических процессов - сорбции и термической конденсации водяного пара. Сорбция, включая капиллярную конденсацию, обусловлена свойствами материала и мало зависит от конструкции ограждения. Термическая конденсация зависит как от конструкции, так и от условий эксплуатации ограждения. Таким образом

$$
W_{o}=W_{s}+W_{l}
$$

где $W_{o}$ - равновесная влажность, \% по объему; $W_{s}$ - сорбционная составляющая равновесной влажности; $W_{t}$ - термоконденсационная составляющая равновесной влажности.

Сорбция предшествует термической конденсации, которая возможна лишь по достижении материалом предела сорбционного увлажнения. Поэтому сорбционную составляющую $W_{s}$ равновесной влажности можно принять равной максимальной сорбционной влажности материалов при $t=0^{\circ} \mathrm{C}$ и $\varphi=100 \%$. Термоконденсационная составляющая $W$, зависит от длительности периода времени, в течение которого возможна термическая конденсация. Для всякой ограждающей конструкции существует некоторая расчетная температура внешней среды $t_{\text {н.расч. }}$, которая соответствует периоду термической конденсации водяного пара в данном ограждении.

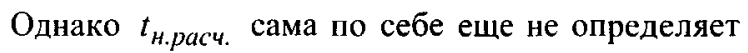
длительность периода термической конденсации и поэтому не является критерием, характеризующим степень увлажнения ограждений за счет термической конденсации. Чтобы получить критерий, учитывающий еще и климатические условия, расчетные параметры внешней среды для всякой ограждающей конструкции необходимо отнести к фактическим климатическим. Выразим расчетную температуру

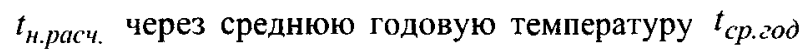
и амплитуду годовых колебаний среднемесячных температур $A_{t}$ для данного географического района [2]:

$$
t_{\text {H.pacч. }}=t_{c p . \text { год }}+\eta \cdot A_{t},
$$

откуда получаем безразмерный козффициент

$$
\eta=\frac{t_{\text {H.pacч. }}-t_{c p . z o d}}{A_{t}}
$$

который зависит от климатических условий. Поскольку влажность ограждений зависит от тех же факторов, можно полагать, что коэффициент $\eta$ является критерием эксплуатационного влажностного состояния ограждения и что равновесная влажность является функцией этого критерия. 


\section{3. Исследование равновесной влажности огражде- ний по натурным наблюдениям}

\section{1. Методика исследований}

В работе использованы данные натурных обследований ограждающих конструкций жилых зданий (рис. 1), а также зданий с влажными и мокрыми помещениями, проведенные институтом "Термоизоляция" [4, 5] и другими научно-исследовательскими организациями [6-15].

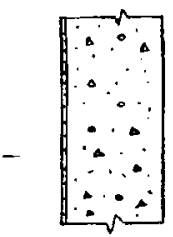

64

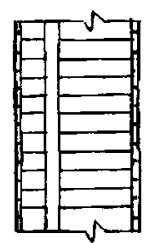

2.1.13 1 2

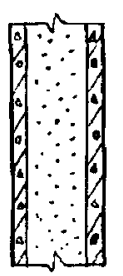

959

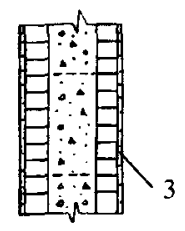

$2,14,(7), 10$
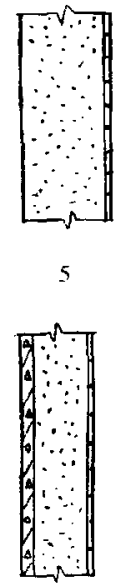

952

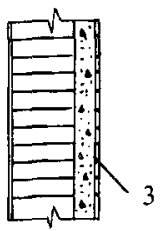

$2 \quad 1 \quad 4 .(7)$
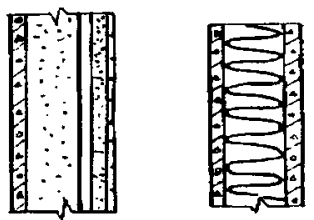

$9511,13,8$

9109

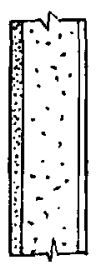

652

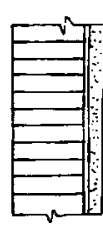

113,8
Стены мокрых помещений зданий [13-15]

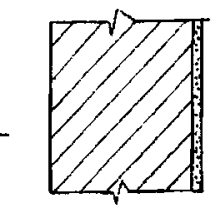

$12(2)$

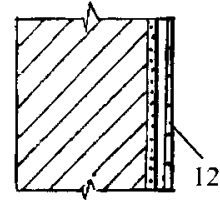

$1 \quad 2,11.2$

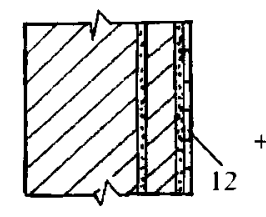

$1 \quad 2,11,1,2$
Рис. 1. Ограждающие конструкции зданий [4-12]: 1 кирпичная кладка; 2 - штукатурка; 3 -сухая штукатурка; 4 - шлакобетон; 5 -ячеистый бетон; 6 фактурный слой; 7 -шлак; 8 - гипсобетон; 9 железобетон; 10 - минераловатные плиты (маты); 11 пароизоляция (рубероид); 12 - облицовка; 13 воздушная прослойка

Fig 1. Types of enclosures: 1 - masonry; 2 - stucco; 3 plaster board; 4 - slag concrete; 5 - porous concrete; 6 fïnish layer; 7 -slag; 8 - gypsum concrete; 9 - ferro-concrete; 10 -rockwool slabs (mats); 11 - vapour insulation (prepared roofing paper); 12 - surface finish; 13 -air gap

\section{2. Результаты определения равновесной влаж- ности ограждений по натурным наблюдениям}

Результаты обработки натурных наблюдений приведены на рис. 2 и 3. Расположение точек (данных натурных наблюдений) свидетельствует об определенной зависимости равновесной влажности материалов от величины критерия $\eta$. В дальнейшем для каждого из ограждений рассчитывали сорбционную $W_{s}$ (равную максимальному сорбционному увлажнению материалов при $\mathrm{t}=0^{\circ} \mathrm{C}$ и $\varphi=100 \%$ ) [ 16 , 17] и термоконденсационную $W_{t}=\left(W_{o}+W_{s}\right)$ составляющие равновесной влажности".

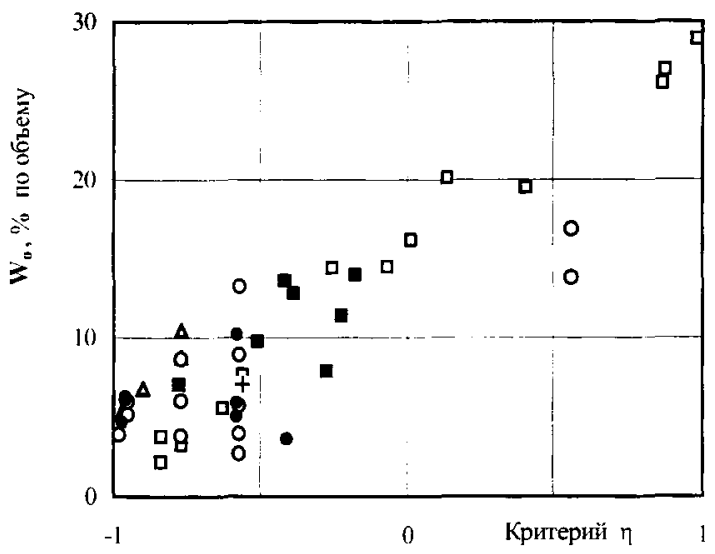

Рис. 2. Зависимость равновесной влажности ограждений от величины критерия $\eta$ по данным натурных наблюдений: $\square$ - кладка из сплошного глиняного обыкновенного и силикатного кирпича $[6,9,10,13$ 15]; $\Delta$ - шлакобетон [8, 9]; - пенобетон, сиперекс $[6,8] ; 0, \bullet-$ ячеистый бетон негидрофобизированный и гидрофобизированный [4]

Fig 2. The equilibrium moisture dependence on criteria $\eta$ according to in-situ investigations: $\square$ - traditional ceramic and sand-lime brick masonry $[6,9,10,13-15]$; $\Delta$ - slag concrete $[8,9] ; \boldsymbol{~ - ~ f o a m ~ c o n c r e t e ~}[6,8] ; 0, \bullet$ - porous concrete without and with water repellent treatment [4]

На рис. 4 и 5 термоконденсационная составляюшая равновесной влажности представлена в зависимости от величины критерия $\eta$. В интервале $(-1)<\eta<0$ эту зависимость можно представить формулой:

$$
W_{o}=W_{s}+W_{t}^{o}(\eta+1) \text {, }
$$

\footnotetext{
" Подробные результаты обработки натурных наблюдений приведены в [18].
} 
где $W_{t}^{0}-$ термоконденсационная составляющая $W_{t}$ при $\eta=0$.

На основании регрессионного анализа данных, представленных на рис. $4, W_{t}^{0}$ составляет $12,3 \%$ по объему, а представленных на рис. $5-0,028 \%$ по объему.

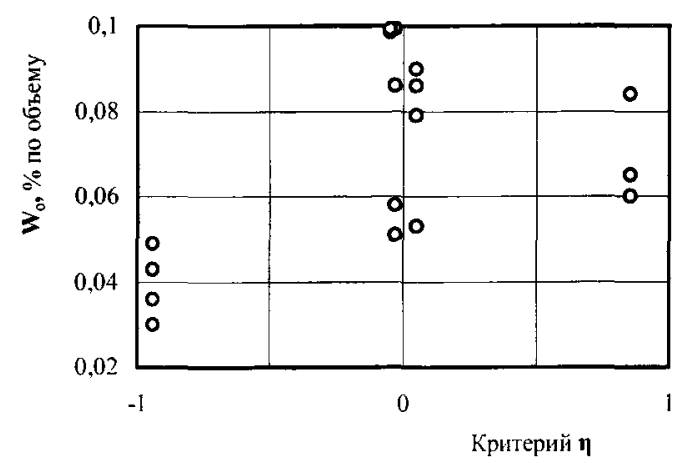

Рис. 3. Зависимость равновесной влажности минераловатного утеплителя традиционных ограждаюших конструкций от величины критерия $\eta$ по данным натурных наблюдений $[4,5]$

Fig 3. The mineral wool warm-keeping lagging's equilibrium moisture dependence on criteria $\eta$ for traditional building enclosures according to data of in-situ investigations $[4,5]$

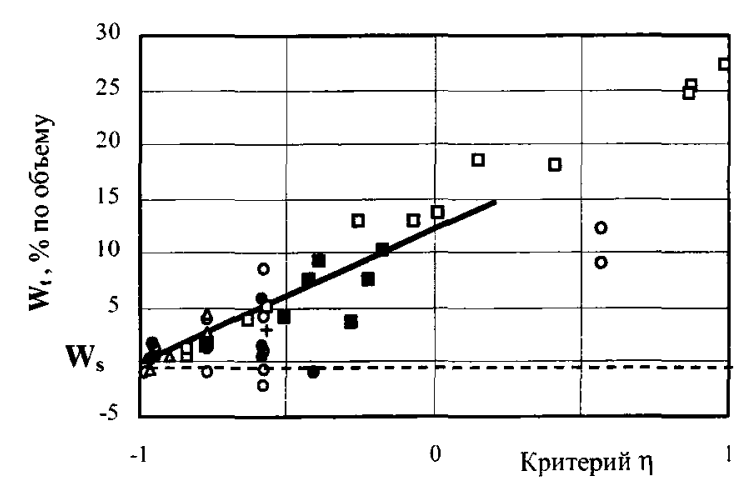

Рис. 4. Зависимость термоконденсащионной составляющей равновесной влажности ограждений от величины критерия $\eta$ по данным натурных наблюдений (см. обозначения к рис. 2)

Fig 4. The enclosure's thermal condensation moisture component dependence on criteria $\eta$ according to data of in-situ investigations (see notation of Fig 2)

При значениях $\eta$ меньше -1 равновесная влажность не выходит за пределы сорбционного увлажнения. При положительных значениях $\eta$ она может зависеть не только от величины критерия $\eta$, но и

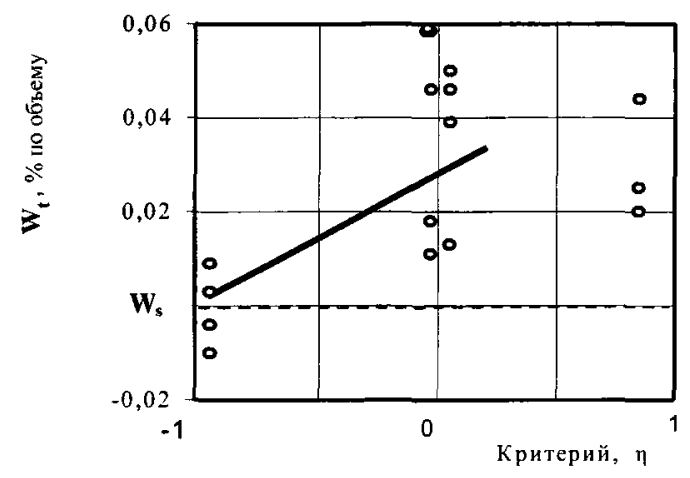

Рис. 5. Зависимость термоконденсационной составляющей равновесной влажности мннераловатного утеплителя традиционных ограждающих конструкций от величины критерия $\eta$ по данным натурных наблюдений $[4,5]$

Fig 5. The enclosure's thermal condensation moisture component dependence on criteria $\eta$ for traditional enclosures according to data of in-situ investigations $[4,5]$

от плотности и предела водонасыщения материалов. Однако это относится к той величине влажности материалов, которая не допустима в реальных конструкциях.

Подставив в формулу (4) значение 3 по формуле (3) получим:

$$
W_{o}=W_{s}+\frac{W_{t}^{0}}{A_{t}}\left[t_{\text {H.pacu. }}-\left(t_{c p .2 o \partial}-A_{t}\right)\right] .
$$

Здесь $\left(t_{c p . г о}-A_{t}\right)$ - не что иное, как наиболее низкая среднемесячная температура для данного географического пункта. Обозначив эту температуру через $t_{\text {н.мин }}$, получим формулу для расчета равновесной влажности:

$$
W_{o}=W_{s}+\frac{W_{t}^{0}}{A_{t}}\left(t_{\text {H.pacч. }}-t_{\text {H.1ulH }}\right) .
$$

По данным натурных наблюдений наиболее интенсивное изменение влажности ограждений, например, стен, происходит в течение холодного периода года, когда градиенты температур ограждений значительны по величине. Позтому, исходя из принципов расчета влажностного режима ограждений, температура $t_{\text {н.расч. }}$ в формуле (6) принимается равной средней температуре наружного воздуха месяцев с отрицательными среднемесячными температурами $t_{\text {н.o }}$. Температура $t_{\text {н.мин }}$ - среднемесячная температура наиболее холодного месяца. 
3.3. Влияние климатических параметров Литвы на термоконденсационную составляющую равновесной влажности ограждений

Основным показателем климата холодного периода (месяцев с отрицательными среднемесячными температурами) является изменение температуры наружного воздуха. После обозначения в формуле (6)

$$
\frac{t_{\text {H.o }}-t_{\text {H.AuH }}}{A_{t}}=\alpha
$$

как параметра климата холодного периода в табл. 1 представлены результаты статистической обработки его значений по данным климатологических наблюдений [19]. На их основании для расчета величины термоконденсационной составляющей равновесной влажности ограждающих конструкций значение параметра климата холодного периода может быть принято $\alpha=0,2$ как для всей территории Литвы, так и для районов морского побережья. Отсюда окончательно формулу (6) можно привести к виду:

$$
W_{0}=W_{s}+\alpha W_{t}^{0},
$$

которая учитывает влияние климатических условий Литвы на термоконденсационную составляющую равновесной влажности ограждающих конструкций.

\section{4. Расчет величины возможной равновесной влажности материалов ограждений в климати- ческих условиях Литвы}

На основании представленных результатов натурных обследований ограждений и с учетом возможной степени воздействия на них климатических условий Литвы сделана попытка оценить возможную величину равновесной влажности для отдельных строительных материалов, которую следовало бы учитывать при установлении проектного значения их коэффициента теплопроводности.

Вычисленные возможные значения равновесной влажности отдельных неорганических строительных материалов в ограждающих конструкциях представлены в табл. 2, в которую включены только те строительные материалы, для которых по данным натурных обследований определена термоконденсационная составляющая $W_{t}^{0}$ или с достаточной условностью может быть применена к ним, например, ячеистые бетоны различной плотности, керамзитобетон и др. В таблице содержатся сведения о максимальной сорбционной влажности $W_{s}$, равновесной влажности материала в ограждающей конструкции $W_{0}$, а также для сравнения приведено расчетное значение $W_{\text {раси }}$ влажности материалов для условий эксплуатации

1 таб̆лица. Результаты статистической обработки значений параметра климата холодного периода $\alpha$ для различных районов Литвы

\begin{tabular}{|c|c|c|c|c|c|}
\hline \multirow{2}{*}{$\begin{array}{c}\text { Районы с температурой } \\
t_{\text {ср. гон. }} \text { от }- \text { до, }{ }^{\circ} \mathrm{C}\end{array}$} & \multirow{2}{*}{$\mathrm{t}_{\text {н.о. }},{ }^{\circ} \mathrm{C}$} & \multirow{2}{*}{$\mathbf{t}_{\text {н.мин. }},{ }^{\circ} \mathrm{C}$} & \multirow{2}{*}{$\mathrm{A}_{1},{ }^{\circ} \mathrm{C}$} & \multicolumn{2}{|c|}{$\begin{array}{l}\text { Параметр климата холодного } \\
\text { периода } \alpha \text {, вычисленный по }\end{array}$} \\
\hline & & & & $\begin{array}{c}\text { средним } \\
\text { значениям } \mathrm{t}_{\text {н.мнн. }}\end{array}$ & $\begin{array}{l}\text { максимальным } \\
\text { значениям } t_{\text {н.мин }}\end{array}$ \\
\hline $\begin{array}{l}5,7 \div 6,7 \\
\text { (вся территория Литвы) } \\
6,3 \div 7,2 \\
\text { (зона морского побережья) }\end{array}$ & $\begin{array}{c}-(3,5 \pm 0,2) \\
-0,3\end{array}$ & $\begin{array}{l}-(5,5 \pm 0,2) \\
-(2,1 \pm 0,8)\end{array}$ & $\begin{array}{l}11,1 \\
10,1\end{array}$ & $\begin{array}{l}0,180 \\
0,178\end{array}$ & $\begin{array}{l}0,198 \\
0,257\end{array}$ \\
\hline $\begin{array}{l}5,7 \div 5,9 \\
6,0 \div 6,3 \\
6,7 \\
5,7 \div 6,7 \\
\text { (Вильнюс) } \\
5,7 \div 6,0 \\
\text { (Пригород Вильнюса) } \\
6,3 \div 6,6 \\
\text { (Каунас) }\end{array}$ & $\begin{array}{l}-(3,6 \pm 0,8) \\
-(3,4 \pm 0,7) \\
-(3,2 \pm 1,7) \\
-(3,5 \pm 1,4) \\
-(3,8 \pm 1,9) \\
-(3,0 \pm 1,6)\end{array}$ & $\begin{array}{l}-(5,6 \pm 0,) 6 \\
-(5,5 \pm 0,3) \\
-(5,0 \pm 0,5) \\
-(6,0 \pm 1,1) \\
-(6,2 \pm 2,0) \\
-(5,1 \pm 0,1)\end{array}$ & $\begin{array}{l}11,0 \\
11,2 \\
11,5 \\
11,6 \\
11,5 \\
11,2\end{array}$ & $\begin{array}{l}0,182 \\
0,188 \\
0,157 \\
0,216 \\
0,209 \\
0,188\end{array}$ & $\begin{array}{l}0,236 \\
0,214 \\
0,200 \\
0,310 \\
- \\
\\
0,196\end{array}$ \\
\hline
\end{tabular}

Table 1. The results of matematical-statistical treatment of cold season climatic parameter $\alpha$ values for Lithuanian regions 
2 таблица. Возможные величины равновесной влажности неорганических ${ }^{*}$ строительных материалов в ограждающих конструкциях зданий

Table 2. The possible equilibrium moisture of inorganic materials in building enclosures

\begin{tabular}{|c|c|c|c|c|c|c|c|}
\hline \multirow{3}{*}{ Материалы и изделия } & \multirow{3}{*}{$\begin{array}{c}\text { Плотность, } \\
\mathrm{K \Gamma} / \mathrm{M}^{3}\end{array}$} & \multirow{3}{*}{$\begin{array}{c}\mathrm{W}_{\mathrm{s}}^{* *)}, \% \\
\text { по объему }\end{array}$} & \multicolumn{2}{|c|}{$\mathbf{W}_{0}, \%$} & \multicolumn{3}{|c|}{$\mathrm{W}_{\text {расч. }}, \%$ по массе согласно } \\
\hline & & & \multirow{2}{*}{ nо объему } & \multirow{2}{*}{ по массе } & \multirow{2}{*}{$\begin{array}{c}\text { RSN } \\
143-92\end{array}$} & \multicolumn{2}{|c|}{ СНиП II-3-79** } \\
\hline & & & & & & $\mathrm{A}$ & $\mathbf{b}$ \\
\hline $\begin{array}{l}\text { Бетоны ячеистые } \\
\text { (газобетоны) }\end{array}$ & $\begin{array}{l}1000 \\
800 \\
600 \\
400 \\
300\end{array}$ & $\begin{array}{l}6,9 \\
4,3 \\
3,8 \\
3,3 \\
2,7\end{array}$ & $\begin{array}{l}9,4 \\
6,8 \\
6,3 \\
5,8 \\
5,2\end{array}$ & $\begin{array}{c}9,4 \\
8,5 \\
10,5 \\
14,5 \\
17,3\end{array}$ & $\begin{array}{l}6 \\
6 \\
5 \\
5 \\
5\end{array}$ & $\begin{array}{c}10 \\
10 \\
8 \\
8 \\
8\end{array}$ & $\begin{array}{l}15 \\
15 \\
12 \\
12 \\
12\end{array}$ \\
\hline Пенобетон & $\begin{array}{l}800 \\
600 \\
500\end{array}$ & $\begin{array}{l}5,5 \\
4,2 \\
3,7\end{array}$ & $\begin{array}{l}8,0 \\
6,7 \\
6,2\end{array}$ & $\begin{array}{l}10,0 \\
11,2 \\
12,4\end{array}$ & $\begin{array}{l}6 \\
5 \\
5\end{array}$ & $\begin{array}{l}10 \\
8 \\
8\end{array}$ & $\begin{array}{l}15 \\
12 \\
12\end{array}$ \\
\hline Пеносиликат & 800 & 3,4 & 5,9 & 7.4 & 6 & 10 & 15 \\
\hline $\begin{array}{l}\text { Минераловатные } \\
\text { изделия }\end{array}$ & $\leq 100$ & 0,04 & 0,046 & 0,9 & $2 ; 5 ; 0,5$ & 2 & 5 \\
\hline $\begin{array}{l}\text { Керамзитобетон на } \\
\text { керамзитовом песке }\end{array}$ & $\begin{array}{l}1000 \\
800\end{array}$ & $\begin{array}{l}8,7 \\
8,2\end{array}$ & $\begin{array}{l}11,2 \\
10,7\end{array}$ & $\begin{array}{l}11.2 \\
13.4\end{array}$ & $\begin{array}{r}\mathrm{I} 0(8) \\
10(8)\end{array}$ & $\begin{array}{r}5(4) \\
5(4) \\
\text { 1а ква }\end{array}$ & $\begin{array}{l}10(8) \\
10(8) \\
\text { песке }\end{array}$ \\
\hline Шлакобетон & $\begin{array}{l}1500 \\
1100\end{array}$ & $\begin{array}{l}6,2 \\
4,5\end{array}$ & $\begin{array}{l}8,7 \\
7,0\end{array}$ & $\begin{array}{l}5,8 \\
6,4\end{array}$ & $\begin{array}{l}8 \\
8\end{array}$ & $\begin{array}{l}5 \\
5\end{array}$ & $\begin{array}{l}8 \\
8\end{array}$ \\
\hline $\begin{array}{l}\text { Строительные } \\
\text { растворы: цементно- } \\
\text { песчаный сложный } \\
\text { известково-песчаный }\end{array}$ & $\begin{array}{l}1800 \\
1700 \\
1600\end{array}$ & $\begin{array}{l}5,6 \\
3,9 \\
4,1\end{array}$ & $\begin{array}{l}8,1 \\
6,4 \\
6,6\end{array}$ & $\begin{array}{l}4,5 \\
3,8 \\
4,1\end{array}$ & $\begin{array}{l}4 \\
4 \\
4\end{array}$ & $\begin{array}{l}2 \\
2 \\
2\end{array}$ & $\begin{array}{l}4 \\
4 \\
4\end{array}$ \\
\hline Засыпка из шлака & $\begin{array}{l}800 \\
600 \\
400\end{array}$ & $\begin{array}{l}3,3 \\
2,4 \\
1,7\end{array}$ & $\begin{array}{l}5,8 \\
4,9 \\
4,2\end{array}$ & $\begin{array}{c}7.2 \\
8,2 \\
10.5\end{array}$ & $\begin{array}{l}- \\
- \\
-\end{array}$ & $\begin{array}{l}2 \\
2 \\
2\end{array}$ & $\begin{array}{l}3 \\
3 \\
3\end{array}$ \\
\hline $\begin{array}{l}\text { Кладка из глиняного } \\
\text { обыкновенного } \\
\text { кирпича на цементно- } \\
\text { песчаном растворе }\end{array}$ & 1800 & 1,5 & 4,0 & 2,2 & 2 & 1 & 2 \\
\hline $\begin{array}{l}\text { Кладка из силикатного } \\
\text { кирпича на цементно- } \\
\text { песчаном растворе }\end{array}$ & 1800 & 2,4 & 4,9 & 2,7 & 5 & 2 & 4 \\
\hline
\end{tabular}

*) В таблице не представлены данные об органических теплоизоляционных материалах (пенополистирол, полиуретан, эковата), так как многолетние натурные наблюдения за конструкциями ограждений зданий с их применением практически отсутствуют.

Для определения возможной величины равновесной влажности органических материалов в ограждающих конструкциях могут быть использованы результаты исследований $[20,21]$, согласно которым существует достаточно точная зависимость между практическим влагосодержанием органических материалов в ограждении и равновесной влажностью в воздухе.

**) Влажность материалов в ограждении, обусловленная процессом сорбции в \% по объему принята равной максимальной сорбционной влажности материалов при $t=0^{\circ} \mathrm{C}$ и определена по таблицам [16, 17] и данным [22-24]. 
ограждений согласно $[25,26]$. Сведения из RSN $143-$ 92' приводятся на том основании, что в STR 2.01.03:1999 поправка $\Delta \lambda_{w}$, учитывающая дополнительное увлажнение материала в ограждении, находится в тесной связи с декларируемым в RSN 14392 расчетным значением влажности материалов в ограждении, практически перенесенным в регламент. Поэтому сравнение вычисленных возможных значений равновесной влажности строительных материалов в ограждающих конструкциях с данными нормативных документов с позиции влажности представляет практический интерес.

С учетом представленных в табл. 2 результатов следует отметить, что для ячеистых бетонов плотностью от 300 до $1000 \mathrm{\kappa \Gamma} / \mathrm{M}^{3}$ и керамзитобетона плотностью $800,1000 \mathrm{\kappa г} / \mathrm{m}^{3}$ в [27] использованы заниженные расчетные значения влажности материалов. Следовательно, и предлагаемые [27] поправки $\Delta \lambda_{w}$, для определения проектного значения их коэффициента теплопроводности требуют уточнения (по нашему мнению, в сторону увеличения).

Сравнение влажных состояний $W_{0}$ и $W_{\text {pacu }}$ других материалов в ограждениях представлено в табл. 2.

\section{4. Выводы}

1. Равновесная влажность $W_{0}$ ограждений представлена как сумма сорбционного $W_{s}$ и термоконденсационного $W_{t}$ увлажнения. Показано, что коэффициент $\eta$ является критерием эксплуатационного влажностного состояния ограждения.

Зависимость равновесной влажности ограждений от величины критерия $\eta$ представлена выражением (4), в котором $W_{t}^{0}$ - термоконденсационная составляющая $W_{t}$ при $\eta=0$ - по данным регрессионного анализа для кладки из сплошного глиняного обыкновенного и силикатного кирпича, ячеистого бетона, керамзитобетона, шлакобетона, засыпки из шлака составляет $12,3 \%$ по объему, а для минераловатных изделий в традиционных ограждающих конструкциях $-0,028 \%$ по объему. Определение $W_{t}^{0}$ для легких неорганических и органических теплоизоляционных материалов, применяемых в современных

I C 1.06.1999 введен STR 2.05.01:1999 взамен RSN 143-92 ограждающих конструкциях зданий, является актуальным и будет возможным при накоплении данных проводимых натурных обследований таких ограждений.

2. Параметр климата холодного периода представлен коэффициентом $\alpha$. Установлено, что для расчета величины термоконденсационной составляющей равновесной влажности ограждений может быть принято значение $\alpha=0,2$ как для всей территории Литвы, так и для районов морского побережья.

3. Осуществлена оценка возможной величины равновесной влажности для отдельных строительных материалов в ограждениях, которая должна учитываться при установлении проектного значения их коэффициента теплопроводности.

\section{Литература}

1. STR 2.09.02:1998 Šildymas, vèdinimas ir oro kondicionavimas // Valstybés žinios, 1999, Nr. 13, p. 54-79.

2. В. Н. Богословский. Строительная теплофизика (теплофизические основы отопления, вентиляции и кондиционирования воздуха). М.: Высш. школа, 1982. $415 \mathrm{c}$

3. Н. В. Кобышева. Косвенные расчеты климатических характеристик. Л.: Гидрометеоиздат, 1971. 192 с.

4. Провести научно-исследовательские работы по изучению долговечности эффективных утеплителей (трехслойных панелей, элементов из ячеистого бетона) и разработать рекомендации по их применению (81.17.03): Отчет / ВНИИ „Теплоизоляция“. № ГР 01830051884. Вильнюс, 1985. 148 с.

5. Исследование долговечности, эксплуатационных свойств и техническое обоснование применения минераловатных утеплителей, изготовленных на различных связуюших в ограждаюших конструкциях зданий: Отчет / ВНИИ „Теплоизоляция“. № ГР 70030902. Вильнюс, 1970. 120 с.

6. Б. Ф. Васильев. Натурные исследования температурновлажностного режима жилых зданий. М.: Изд-во литературы по строительству, 1967. 130 с.

7. Б. Ф. Васильев. Натурные исследования температурновлажностного режима крупнопанельных жилых зданий. М.: Изд-во .литературы по строительству, 1968. $120 \mathrm{c}$.

8. Б. Ф. Васильев. Динамика влажности крупноэлементных стен. Сушка и увлажнение строительных материалов и конструкций. М.: Профиздат, 1968. 98 с.

9. Е. Ю. Брайнина, А. М. Сизов. Натурные наблюдения над облегченными стенами жилых зданий. Исследования - строительная теплотехника. М.: Изд-во литературы по строительству, 1955. $116 \mathrm{c.}$ 
10. Б. Н. Иванов. Некоторые данные о влажности конструктивных элементов жилых зданий перед сдачей в эксплуатацию. Сушка и увлажнение строительных материалов и конструкший. М.: Профиздат, 1968. 112 с.

11. Т. Г. Маклакова. Физико-технические свойства конструкций крупнопанельных жильх зданий. Обобщение итогов натурных и лабораторных исследований. М.: Изд-во литературы по стронтельству, 1966. 139 с.

12. Вопросы долговечности строительных материалов для крупнопанельного домостроения / Под общ. ред. А. Г. Зайцева. М.: Изд-во литературы по строительству, 1963. $52 \mathrm{c}$.

13. Э. М. Ариевич. Причины разрушения и ремонг мокрых помещений бань и прачечных. М.: Изд-во МКХ РСФСР, 1962. 96 c.

14. А. А. Задерман. Гидроизоляция бань и прачечных. М.: Изд-во МКХ РСФСР, 1957. 82 с.

15. А. У. Франчук. Вопросы теории и расчета влажности ограждающих частей зданий. М.: Госстройиздат, 1954 $180 \mathrm{c}$.

16. А. У. Франчук. Таблицы теплотехнических показателей строительных материалов. М.: НИИСФ, 1969. $140 \mathrm{c}$.

17. Л. М. Никитина. Термодинамические параметры и коэффициенты массопереноса во влажных материалах. М.: Энергия, 1968. $620 \mathrm{c}$.

18. Pastaty atitvary termoizoliacinio sluoksnio nuostoviojo (pusiausvyrinio) drègnio priklausomybès nuo skaičiuojamuju klimatinių parametru ir jo nustatymo pagal šiuos parametrus galimybiu tyrimai. Temos Nr. 2 Ataskaita / Termoizoliacijos institutas. Vilnius, 1999. 48 p.

19. RSN 156-94. Statybinè klimatologija. Vilnius, 1995. $136 \mathrm{p}$.

20. И. С. Каммерер. Теплоизоляция в промышленности и строительстве / Пер. с нем. И. С. Утевского и др. М.: Стройиздат, 1965. 378 с.

21. И. С. Пиховкин. Покрытия и кровли промышленных зданий на Севере. Л.: Стройиздат, 1978. $136 \mathrm{c.}$

22. М. С. Доннер. О свойствах низкотемпературных теплоизоляторов // Производство, свойства и применение теплоизоляционных изделий и конструкций. Сборник трудов, Вып. 14 / Минмонтажспецстрой СССР, Главтепломонтаж, НИПИ Теплопроект. М., 1970, с. 33 45.

23. С. С. Ефимов. Метод температурного пересчета изотерм равновесного удельного влагосодержания // Инженерно-физический журнал, 1984, Т. 46, № 2, c. $257-260$.

24. Akmens vatos šilumos izoliacijos gaminių - siūtụ demblių ir plokščiu - vandens garu laidumo ir šilumos laidumo koeficientų eksploatacinèse sąlygose nustatymas. Ataskaita / Termoizoliacijos institutas. Vilnius, 1995. 5 p.

25. RSN 143-92. Pastatų atitvaru šiluminè technika. Vilnius, 1992. $71 \mathrm{p}$.

26. СНиП II-3-79*. Строительная теплотехника / Минстрой России. М.: ГП ЦПП, 1995. 29 с.
27. STR 2.01.03:1 Б.H 999 Statybiniı medžiagu ir gaminiu šiluminių techninių dydžiu deklaruojamosios ir projektinès vertès. Vilnius, 1999. $26 \mathrm{p}$.

İteikta 20000502

\section{PASTATU ATITVARINIU KONSTRUKCIJU NUOSTOVIOJO DRĖGNIO PRIKLAUSOMYBE் NUO SKAIČIUOJAMŲJU KLIMATO PARAMETRŲ}

\section{Gnipas, V. Keršulis, S. Vẻjelis}

Santrauka

Išnagrinètas atitvarinių konstrukcijų nuostoviojo drègnio ryšys su skaičiuojamaisiais klimatiniais parametrais. Atitvaru nuostovusis drègnis $W_{0}$ yra išreikštas sorbcinio $W_{s}$ ir termokondensacinio $W_{t}$ idrèkio suma ir parodyta, kad koeficientas $\eta$ (3) yra eksploatacinio drègminio būvio kriterijus.

Atitvarц nuostoviojo drègnio priklausomybè nuo kriterijaus $\eta$ vertès pateikta (4). Ċia $W_{t}^{0}$ - termokondensacinis dèmuo $W_{t}$, kai $\eta=0$. Bandymu duomenimis, jis lygus $12,3 \%$ (tūrio) pilnaviduriu keraminių ir silikatinių plytų mūrui, taip pat akytajam betonui, keramzitbetoniui, šlakbetoniui, šlako užpildams ir - $0,028 \%$ (tūrio) akmens vatos gaminiams tradicinèse atitvarinèse konstrukcijose (1 pav.).

Šaltojo periodo klimatui ivertinti taikytas parametras $\alpha$ ir nustatyta, kad skaičiuojant atitvarų nuostoviojo drègnio termokondensacini dèmenį Lietuvos klimato sąlygomis $\alpha=0,2$.

Bandymu duomenimis ir atsižvelgiant i galimą klimato parametrų j̇taką atitvaru drègminiam būviui, atliktas galimų atitvarų statybinių medžiagu nuostoviojo drègnio verčių, i kurias turetu būti atsižvelgiama nustatant šị medžiagų šilumos laidumo projektines vertes, ivertinimas ( 2 lentelè).

\section{THE EQUILIBRIUM MOISTURE OF BUILDING ENCLOSURES AS FUNCTION OF CALCULATED CLIMATIC PARAMETERS}

\section{Gnip, V. Keršulis, S. Vèjelis}

\section{Summary}

The climatic parameters influence the equilibrium moisture of building enclosures and their thermal insulating layers. This investigation seeks to find a quantitative correlation between these influence values.

The enclosure equilibrium moisture content $W_{0}$ was expressed as the sum of two components: sorption moisture $W_{s}$ and thermal condensation moisture $W_{t}$ (formula 1). The coefficient $\eta$ was introduced as the maintenance moist state criterion (formula 3), which depends on climatic conditions. It has been used for in-situ investigations of different enclosures (Fig 1) of dwelling houses as well as for damp and wet premises data [4-15]. The results (Fig 2, 3) show the dependence of equilibrium moisture on $\eta$. This dependence has been expressed by (4), where $W_{t}^{0}$ is $W_{t}$ component due to thermal condensation when $\eta=0 . W_{t}^{0}$ is equal to $12,3 \%$ (vol) for ceramic and sand-lime, brick masonry as well as for porous concrete, expanded clay aggregate, slag fillings and is equal 
to $0,028 \%$ (vol) for rock wool products in traditional enclosures (Fig 1).

The parameter $\alpha$ (7) was introduced for estimating cold season climate influence after mathematical statistical treatment of long-term climatic data [19]. It has been found (Table 1) that $\alpha$ may be adopted to be equal to 0,2 when the equilibrium moisture component due to thermal condensation has been calculated for Lithuanian climatic conditions.

The possible equilibrium moisture of various building materials for enclosures has been evaluated by the proposed method and is given in Table 2. The data do not apply to expanded polystyrene, polyurethane foam and cellulose fibre because in-situ investigation data are absent for enclosures with these insulating materials. Table 2 shows that there are several distinctions in given values and corresponding values introduced in abrogated normative documents $[25,26]$ as well as corresponding corrections $\Delta \lambda_{w}$ in valid documents [27] stipulated by additional moisture content of materials in enclosures.

The correction value $\Delta \lambda_{\mathrm{w}}$. must be defined more precisely when thermal conductivity design values are calculated for enclosures with porous concrete or expanded clay aggregates.
Ivan GNIP. Doctor. Head of Building Materials Employment Laboratory. Institute Termoizoliacija, Linkmenu g. 28, LT-2600 Vilnius, Lithuania. E-mail: termosmplab@takas.lt

Doctor (1992). Author and co-author of about 65 publications. Research interests: building thermal insulation materials and products, thermal technical aspects of their employment.

Vladislovas KERŠULIS. Doctor, Senior Researcher. Building Materials Employment Laboratory. Institute Termoizoliacija, Linkmenų g. 28, LT-2600 Vilnius, Lithuania. E-mail: termosmplab@takas.It

Doctor (1970). Author and co-author of about 70 publications. Research interests: thermal technical properties of thermal insulation materials and products.

Sigitas VĖJELIS. PhD student. Institute Termoizoliacija, Linkmenı g. 28, LT-2600 Vilnius, Lithuania. E-mail: termosmplab@takas.lt

A graduate of Vilnius Gediminas Technical University, MSc (1999). Research interests: technical properties of thermal insulation materials and products. 